\title{
EMPREGO DE GEOTÉCNICAS NO ESTUDO DA VARIAÇÃO MORFOLÓGICA DA LAGUNA DO RIO BARRA NOVA, CAUCAIA - CE
}

\author{
Arthur Melo da Nobrega ${ }^{(a)}$, Antônio Emanuel dos Santos Silva ${ }^{(\text {b) }}$, José Wellington Severiano de \\ Lima $^{(\mathrm{c})}$, Davis Pereira de Paula ${ }^{(\mathrm{d})}$
}

(a) Centro de Ciência e Tecnologia, Universidade Estadual do Ceara, arthur.nobrega@aluno.uece.br

(b) Centro de Ciência e Tecnologia, Universidade Estadual do Ceara, antonio.emanuel@ aluno.uece.br

(c) Centro de Ciências Exatas, Universidade Estadual do Vale do Acaraú, wellingtonseveriano@ outlook.com

(d) Centro de Ciência e Tecnologia, Universidade Estadual do Ceará, PROPGEO/UECE, MAG/UVA davis.paula@uece.br

\section{Eixo: DINÂMICA E GESTÃO DE ZONAS COSTEIRAS}

\begin{abstract}
Resumo
As lagunas costeiras são ambientes rebaixados em relação ao nível médio de preamar com comunicação efêmera ou permanente com o mar, esses ambientes desempenham um importante papel no turismo e na dinâmica cultural das comunidades praianas, como é o caso da região litorânea em que a Laguna do rio Barra Nova em Caucaia-CE está localizada. Este é um ambiente com desenvolvimento de múltiplas atividades como pesca artesanal, kitesurf e banho. Destarte, esse estudo tem como objetivo analisar as alterações na morfologia da Laguna do Rio Barra Nova, entre os anos de 2004 e 2016.
\end{abstract}

Palavras chave: Laguna costeira, rio Barra nova, DGPS e imagens de satélite

\section{Introdução}

O litoral é um espaço geográfico de transição entre o meio marinho e o meio terrestre que recebe grande atenção pela sua intensa dinâmica (SILVA, 2001). Ele está sujeito a variação a curto e longo prazo e de macro a microescala. O litoral reúne múltiplos recursos que têm vindo a ser explorados ao longo dos tempos de uma forma cada vez mais intensa, especialmente no que concerne o turismo e o desenvolvimento de comunidades litorâneas no Nordeste brasileiro (URANO et al., 2015).

Nesse contexto, destacam-se as lagunas costeiras, que são ambientes deprimidos abaixo do nível médio da preamar, com comunicação efêmera ou permanente com o mar (FREITAS, 1996). O mesmo autor também destaca que esse tipo de geoambiente ocupa $13 \%$ do litoral mundial, sendo lugar de desenvolvimento de múltiplas atividades como pesca artesanal, kitesurf e banho. Santos e Arantes (2010) destacaram o papel que esses ambientes desempenham no turismo e na dinâmica cultural das comunidades praianas, como é o caso da região litorânea em que a Laguna do rio Barra Nova está inserida. 
Pires (2011) destacou em seu estudo sobre a morfodinâmica da barra de maré efémera da lagoa de Santo

André, que as transformações nas dimensões e geometria de lagunas costeiras são importantes para determinação dos planos de manejo, bem como, para determinação de impactos costeiros induzidos por atividades antrópicas, como a construção de barramentos para capitação de água.

Destarte, esse estudo tem como objetivo analisar as alterações na morfologia da Laguna do Rio Barra Nova, entre os anos de 2004 e 2016. A laguna está localizada no litoral de Caucaia-CE, entre as praias de Tabuba e Icaraí (Figura 1). Este é o trecho costeiro mais visitado por turistas que ingressam no Ceará via Fortaleza, apresentando boas condições para o desenvolvimento do turismo de praia e sol.



Figura 1 - Mapa de Localização da Laguna do rio Barra Nova, Caucaia - CE

\section{Metodologia}

Foram utilizadas imagens do Google Earth para análise visual da área de estudo. Essas imagens foram vetorizadas e georreferenciadas no software ArcGis, versão estudantil. Em cada imagem foram extraídos dados de áreas através da poligonal que representa a geometria da laguna para os anos de 2004, 2010, 2011, 2012, 2013, 2014 e 2015. O polígono foi estabelecido de acordo com o espelho d'água referente a cada ano da laguna. No ano de 2016, a poligonal foi traçada a partir do uso de um DGPS (Differential Global Positioning System) com precisão de $10 \mathrm{~cm}$. No ArcGis foi possível realizar uma sobreposição das imagens e das poligonais e calcular a migração geométrica da laguna do rio Barra Nova.

Entre os dias 15 e 17 de novembro/16 também foi realizada outra campanha de campo para o monitoramento de um evento de ressaca do mar, resultante de um evento astronômico chamado de 


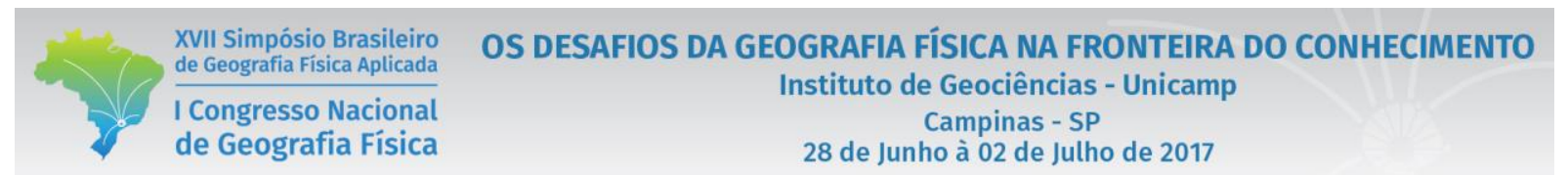

superlua. Durante o campo foram realizadas entrevistas com pescadores, usuários da laguna e moradores, a fim de se observar o entendimento desses agentes sociais sobre as variações na forma da laguna.

Com intuito de melhorar o conhecimento das forçantes que determinam a migração desse sistema lagunar foram coletados dados de precipitação no site da Fundação Cearense de Meteorologia e Recursos Hídricos. Também foram observados dados de ondas no site do Surfguru e maré na Diretoria de Hidrografia e Navegação.

\section{Resultados}

Os vetores que representam os polígonos geométricos da laguna do rio Barra Nova para cada ano analisado estão dispostos na Figura 2. A imagem que está sendo sobrepostas pelos vetores é datada de 19/04/16, isso permite observar as transformações ocorridas, especialmente no que concerne abertura e o fechamento da barra.
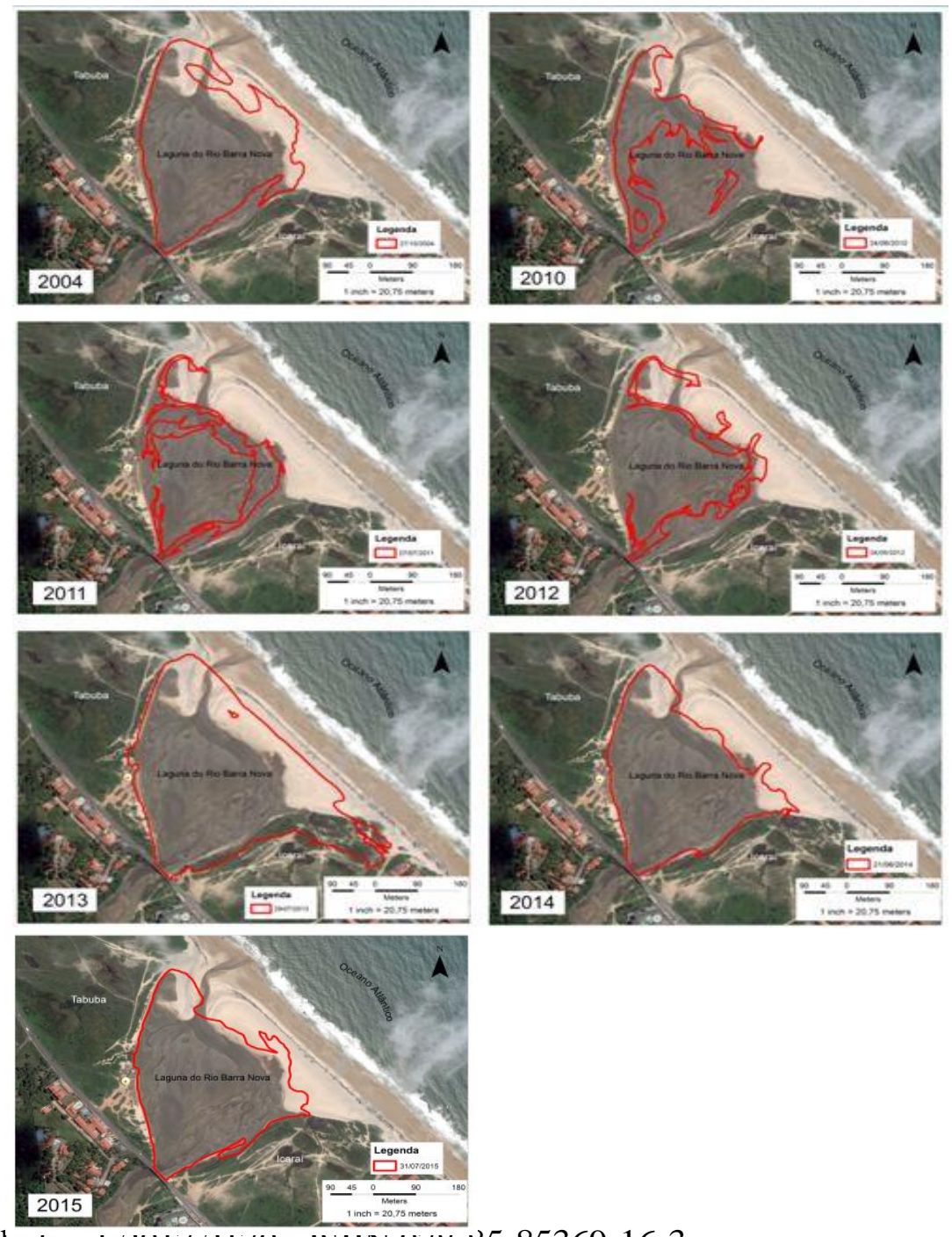


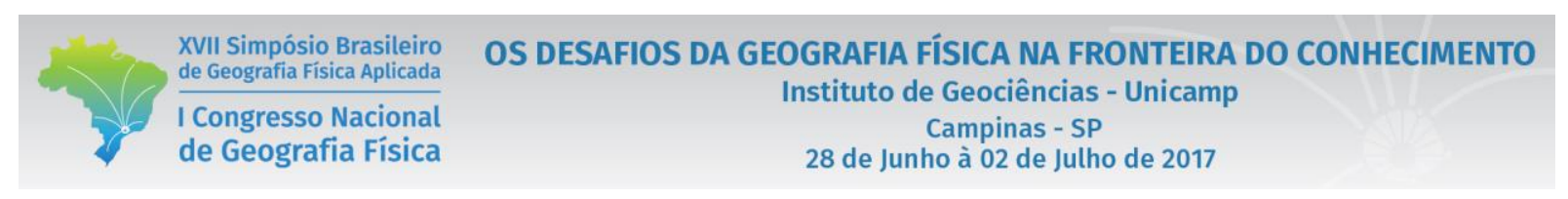

Figura 2 - Variação anual na geometria da área da Laguna do rio Barra Nova

Na figura 2 também é perceptível que em todos os anos houveram mudanças significativas na morfologia da laguna, mas nos anos de 2010, 2011 e 2012 ocorreram as mudanças mais significativas, com tendência para diminuição do espelho de água da laguna. Nos três anos foi observado que a barra da laguna estava aberta, o que aumenta o fluxo de águas em direção ao mar, contribuindo para essa diminuição do espelho de água e para alterações na geometria da laguna. Além disso, nos anos de 2010 e 2012, a precipitação total registrada para o munícipio foi baixo da média histórica para o Ceará (Tabela I).

Tabela I - Dados referentes as alterações na geometria da Laguna Barra Nova em comparação com as médias pluviométricas anuais no estado do Ceará

\begin{tabular}{c|ccc}
\hline ANOS & $\begin{array}{c}\text { ÁREA DA LAGUNA } \\
\left(\mathbf{m}^{\mathbf{2}}\right)\end{array}$ & $\begin{array}{c}\text { SITUAÇÃO DA } \\
\text { BARRA }\end{array}$ & $\begin{array}{c}\text { PRECIPITAÇÃO ANUAL } \\
(\mathbf{M M})\end{array}$ \\
\hline $\mathbf{2 0 0 4}$ & 102573.75 & FECHADA & 1226,2 \\
$\mathbf{2 0 1 0}$ & 37170,69 & ABERTA & 504,2 \\
$\mathbf{2 0 1 1}$ & 22432,04 & ABERTA & 1186,7 \\
$\mathbf{2 0 1 2}$ & 14397,76 & ABERTA & 417 \\
$\mathbf{2 0 1 3}$ & 151195,67 & FECHADA & 465,7 \\
$\mathbf{2 0 1 4}$ & 105916,22 & FECHADA & 565,4 \\
$\mathbf{2 0 1 5}$ & 104916,22 & FECHADA & 885,2 \\
\end{tabular}

$\mathrm{Na}$ entrevista realizada com os pescadores artesanais da laguna, eles foram enfáticos em afirmar que o volume de água da laguna tende a diminuir quando sua barra está aberta. Essa constatação corrobora com os dados disponíveis na tabela 1, além de permite inferir que o senso comum dos usuários locais pode indicar tendência morfológicas desse sistema natural.

Em situação oposta aos anos citados anteriormente, no ano de 2013, foi observado um aumento significativo da área do espelho de água, mesmo com um índice pluviométrico muito baixo, porém com uma situação de barra fechada. Deste modo, é possível indicar que há uma barra de maré efêmera.

\section{Conclusão}

Atualmente, o uso da laguna ocorre de forma intensa e desordenada, pois não existem indicações de espaços para realização de atividades dissonantes, como por exemplo, uma delimitação para a prática do 


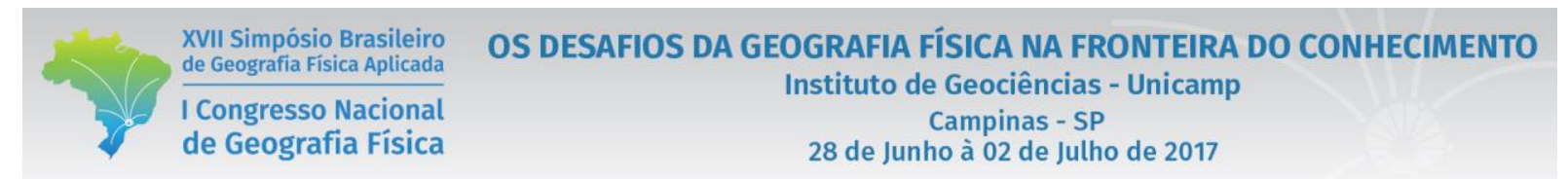

Kitesurf. Além disso, há uma ocupação conflituosa entre pescadores, banhistas e kitesurfistas, que dividem o mesmo espaço físico.

Os resultados permitem inferir que entre os anos de 2004 e 2016, a morfologia da laguna sofreu constante alteração, principalmente por sua barra está ou não em comunicação com a mar. Mas se torna necessários mais estudos para avaliar melhor a influência da barra na variação morfológica da laguna do rio Barra Nova. Deste modo, o estudo da abertura ou fechamento da barra da laguna deve passar por uma modelagem computacional para evidenciar as condições de agitação marítima ou de condições hidroclimáticas extremas que são necessárias para isso.

Assim sendo, o estudo em longo prazo sobre a morfologia e a dinâmica da laguna é de fundamental importância para auxiliar na gestão desse geoambiente, que apresenta importância para o desenvolvimento socioeconômico local.

\section{Agradecimentos}

Ao CNPq pelo financiamento do projeto "Impactos costeiros no litoral de Caucaia (Ceará, Brasil) induzidos pelas obras costeiras construídas a sotamar e pelas ressacas do mar (Processo: 483811/2013-0) e a UECE pela concessão de uma bolsa.

\section{REFERENCIAS}

FREITAS, Maria da Conceição. Lagunas costeiras: ambientes em evolução. Seminário sobre Lagunas Costeiras e Ilhas-barreira da Zona Costeira de Portugal. Associação Eurocoast-Portugal, p. 107-123, 1996.

SANTOS, R. J.; ARANTES, E. M. Turismo e Dinâmica Cultural em uma Comunidade de Pescadores Artesanais: o Caso do Farol de Santa Marta em Laguna (SC). Revista Brasileira de Pesquisa em Turismo, v.4, n. 1, p. 5-23, 2010.

SILVA, Carlos Pereira da. Gestão Litoral: integração de estudos de percepção da paisagem e imagens digitais na definição da capacidade de carga de praias. O Troço Litoral S. Torpes-Ilha do Pessegueiro. 2001.

URANO, D. G.; COCHAND, A.; FIGUEIREDE, S. L.; NOBREGA, W. R. M.; SONAGLIO, K. E. Turismo e Desenvolvimento em Comunidades Litorâneas do Nordeste Brasileiro: Os Casos de Canoa Quebrada, CE, e Maracajaú, RN. Revista Rosa dos Ventos Turismo e Hospitalidade, v. 7, n. 4, p. 574-590, out-dez, 2015. 